\title{
ARTICLE
}

\section{The Concept of Essential Use: A Novel Approach to Regulating Chemicals in the European Union}

\author{
Kathleen Garnett* and Geert Van Calster** (우
}

\begin{abstract}
This article examines 'essential use' as a novel form of regulatory control. An essential use approach to the regulation of potentially hazardous chemicals has not been used extensively (if at all) in European Union (EU) regulatory law and warrants further consideration. Essential use, as initially proposed by scientists and later referred to in the EU 2020 Chemicals Strategy for Sustainability, is a radical departure from the current method of regulating hazardous substances. The purpose of this article is to contribute to legal scholarship on essential use by (i) scoping its origins in United States law and subsequently in international law; (ii) noting its limited incorporation into the EU legal order over the past 30 years; (iii) analyzing how it could be further incorporated into the EU legal order; and (iv) considering the impact of such a move on the future regulation of hazardous substances in the EU.
\end{abstract}

Keywords: PFAS, Toxic-free Europe, Chemicals Strategy for Sustainability, Risk analysis, Essential use

\section{INTRODUCTION}

Per- and polyfluoroalkyl substances (PFAS) are a group of man-made chemicals which includes perfluorooctanoic acid (PFOA), perfluorooctane sulfonic acid (PFOS), GenX, and many other chemicals. ${ }^{1}$ They are synthetic (man-made) organofluorine chemical

* Wageningen School of Law, Wageningen (The Netherlands).

Email: kathleen.garnett@wur.nl.

** University of Leuven (Belgium), King's College, London (United Kingdom), and Monash University, Melbourne (Australia). Practising member of the Belgian Bar.

We are grateful to the peer reviewers for constructive advice and to Diana Maria Lica of Leuven Law for footnote optimization. Funding, upon condition of the fullest scholarly independence, for some of our recent research time into hazardous substances regulation came from Kemikalieninspektionen - the Swedish Chemical Agency, as well as CEFIC - the European Chemical Industry Council, and the Research Council at KU Leuven.

1 United States (US) Environmental Protection Agency (EPA), 'Basic Information on PFAS', available at: https://www.epa.gov/pfas/basic-information-pfas. 
compounds with multiple fluorine atoms attached to an alkyl chain. Their persistent environmental impact has also earned them the name 'forever chemicals', a popularized version of the more jargonistic 'persistent organic pollutants' (POPs). 'Teflon' (nonstick household cooking equipment) is the most popular trade-marked application, but PFAS are also used in food contact materials, firefighters' protective equipment, wastewater treatment plants, foams and cleaning products.

In 2015, the Global PFAS Science Panel, which consists of academics, first proposed the idea of regulating PFAS as a group of substances in relation to their function in society under the new concept of 'essential use'. ${ }^{2}$ Their call was later repeated in the 2018 'Zürich Statement on Future Actions on Per-and Polyfluoroalkyl Substances (PFASs)', 3 and subsequently developed and expanded in a paper published in Environmental Science: Processes \& Impacts with Ian Cousins as lead author. ${ }^{4}$

Institutions of the European Union (EU) have taken an active interest in 'essential use' and 'non-essential use', referencing the terms in a number of EU policy papers; these include:

- Conclusions of the Council of Ministers of the EU meeting in June 2019, which called on the European Commission to prepare an action plan to eliminate all nonessential uses of PFAS; ${ }^{5}$

- European Environment Agency (EEA) Briefing Note on 'Emerging Chemical Risks in Europe: PFAS'; ${ }^{6}$

- 'Elements for an EU Strategy on PFASs', a report presented to other EU Member States during the European Environment Council on 19 December 2019 by Denmark, the Netherlands, Sweden and Luxembourg; ${ }^{7}$ and

- a call by five EU Member States to prepare and submit a REACH restriction dossier on PFAS. ${ }^{8}$

2 A. Blum et al., 'The Madrid Statement on Poly- and Perfluoroalkyl Substances (PFASs)' (2015) 123(5) Environmental Health Perspectives, pp. A107-A111.

3 A. Ritscher et al., 'Zürich Statement on Future Actions on Per- and Polyfluoroalkyl Substances (PFASs)' (2018) 126(8) Environmental Health Perspectives, pp. 084502-1-5.

4 I. Cousins et al., 'The Concept of Essential Use for Determining When Uses of PFASs Can Be Phased Out' (2019) 21(11) Environmental Science: Processes \& Impacts, pp. 1803-15.

5 General Secretariat of the Council, Towards a Sustainable Chemicals Policy Strategy of the Union: Council Conclusions, 26 June 2019, Document 10713/19, para. 14, available at: https://www.consilium. europa.eu/media/40042/st10713-en19.pdf (Council Conclusions).

6 EEA, 'Emerging Chemical Risks in Europe: “PFAS”', 12 Dec. 2019, available at: https://www.eea.europa. eu/themes/human/chemicals/emerging-chemical-risks-in-europe.

7 Authors unspecified, 'Elements for an EU-Strategy for PFASs', Dec. 2019, available at: https://www.regjeringen.no/contentassets/1439a5cc9e82467385ea9f090f3c7bd7/fluor-eu-strategy-forpfass-december-19.pdf.

8 European Chemicals Agency, 'Five European States Call for Evidence on Broad PFAS Restriction', 11 May 2020, ECHA/NR/20/13, available at: https://echa.europa.eu/-/five-european-states-call-for-evidence-on-broad-pfas-restriction. Part of the call for evidence, Q18, makes specific reference to essential and non-essential use. 
Most recently, essential use has been explored and promoted as a regulatory tool in the Commission's 'Chemicals Strategy for Sustainability: Towards a Toxic Free Europe' (2020 Chemicals Strategy). ${ }^{9}$

This article focuses on PFAS. However, as Cousins and co-authors acknowledge, essential and non-essential use could be used as a means of regulatory control in other areas, such as foodstuffs and additives, plant protection products, biocides, electronic equipment, waste, and water. ${ }^{10}$ The article is a scoping exercise, the purpose of which is to inform and extend legal scholarship in the field of regulatory oversight of hazardous substances, using PFAS as a benchmark. It is not our intention in this article to deliver an encyclopaedic overview of all legislation that is potentially affected by essential use. We use the Cousins paper as a yardstick to compare and contrast existing approaches for the simple reason that, to date, it is the most comprehensive study of how essential use could be operationalized in EU chemicals legislation.

The exploratory nature of this article also means that it is premature to attach much importance to the term 'essential use' as an 'approach', 'principle', 'concept', 'methodology', or 'idea'. In this article we frequently use 'concept'. This highlights the novelty of approaching regulation from an essential use angle, and emphasizes that it is a change from the status quo. We do not, however, take a position in the more conceptual debate on essential use as a 'principle' in a Hartian or Dworkinian sense. ${ }^{11}$

This article begins by mapping how essential and non-essential use was first incorporated into United States (US) and later into international law. We note that the concept lay dormant in international environmental law as a means of regulatory control, while risk analysis became the preferred method of regulating hazardous substances from the mid-1990s. We then examine if and when 'essential use' - in so many words or in practice as proposed by Cousins and co-authors - has been used in EU regulation to date. In the realm of EU law we find that where the term 'essential use' does appear, it does so in a limited way and not in the manner proposed by Cousins. Finally, we examine, from a practical point of view, whether essential use might be included de lege ferenda into the body of EU law and, if so, what impact this may have on the future regulation of potentially hazardous substances.

It should be stressed that this article is not an evaluation or commentary on the benefits or drawbacks of essential use. Rather, the intention is to examine how essential and non-essential uses differ from existing rules governing hazardous substances, and the potential impacts of the incorporation of these concepts into chemicals-related legislation. We believe that exploring the concept of essential use will be of even greater interest now that the Commission has chosen explicitly to use it as a tool for phasing out PFAS, ${ }^{12}$

9 European Commission, 'Chemicals Strategy for Sustainability: Towards a Toxic Free Environment', 14 Oct. 2020, COM(2020) 667, available at: https://ec.europa.eu/environment/pdf/chemicals/2020/10/ Strategy.pdf.

10 Cousins et al., n. 4 above, p. 1803.

11 See N. de Sadeleer, Environmental Principles: From Political Slogans to Legal Rules, $2^{\text {nd }}$ edn (Oxford University Press, 2020).

12 Commission Staff Working Document, 'Poly- and Perfluoroalkyl Substances (PFAS)', 14 Oct. 2020, SWD(2020) 249, available at: https://ec.europa.eu/environment/pdf/chemicals/2020/10/SWD_PFAS.pdf. 
and has expressed a wish to expand essential use to other areas of regulatory oversight. ${ }^{13}$ The Commission itself, however, acknowledges that before essential use can be adopted as a regulatory tool, it is first necessary to define its parameters; only then can essential use be applied coherently and uniformly across related EU legislation. ${ }^{14} \mathrm{~A}$ scoping exercise that compares and contrasts the existing approach and methodology based largely on risk analysis with that proposed by Cousins and co-authors is thus a useful beginning.

\section{PFAS: HOW TO DEAL WITH 'FOREVER CHEMICALS'}

Referring to a report by the Organisation of Economic Co-operation and Development (OECD) and the United Nations Environment Programme (UNEP) on PFAS, ${ }^{15}$ Cousins and co-authors estimate that up to 4,700 PFAS chemicals have been produced since the 1940s, and are widely used in both consumer goods and industrial applications. This family of chemicals and many of their substitutes are considered problematic in that:

[they are] highly mobile and move readily into ground and surface waters once released into the environment where they can reside for decades to centuries. As a result of their high environmental persistence, widespread use and release of any PFAS, even polymeric PFASs, will lead to irreversible global contamination and exposure of wildlife and humans, with currently unknown consequences. ${ }^{16}$

Studies reveal high concentrations of hazardous PFAS in the water, soil, and air in Dordrecht (the Netherlands), Veneto (Italy), and Antwerp (Belgium) - all home to chemical factories that produce PFAS. ${ }^{17}$ The damaging and toxic nature of PFAS was highlighted in a report presented to the Council of the European Union by Sweden, the Netherlands, Denmark, and Germany entitled 'Elements for an EU-Strategy for PFASs', in which it was noted that, because of their persistence in the environment, PFAS and their substitutes can have a detrimental impact on humans, the environment and biodiversity. ${ }^{18}$ The potentially damaging effect of PFAS on public health, the environment and biodiversity was also highlighted in a recent EEA Report. $^{19}$

The nature of this group of chemicals, as well as their sheer number, has led to growing calls from some EU Member States to regulate them more efficiently. ${ }^{20}$ One avenue being explored by Cousins and co-authors is that of essential and non-essential use - an

$13 \operatorname{COM}(2020) 667$, n. 9 above, p. 10.

14 Ibid., p. 10.

15 OECD/UNEP, 'Toward a New Comprehensive Global Database of Per- and Polyfluoroalkyl Substances (PFASs): Summary Report on Updating the OECD 2007 List of Per- and Polyfluoroalkyl Substances (PFASs)', 4 May 2018, ENV/JM/MONO(2018)7, available at: https:/www.oecd.org/officialdocuments/publicdisplaydocumentpdf/?cote=ENV-JM-MONO(2018)7\&doclanguage=en.

16 Cousins et al., n. 4 above, p. 1804.

17 G. Goldenman et al., 'The Cost of Inaction: A Socioeconomic Analysis of Environmental and Health Impacts Linked to Exposure to PFAS' (2019) Nordic Council of Ministers, available at: http://norden. diva-portal.org/smash/get/diva2:1295959/FULLTEXT01.pdf.

18 Elements for an EU-Strategy on PFAS, n. 7 above, p. 4.

19 EEA, n. 6 above.

20 Elements for an EU-Strategy on PFAS, n. 7 above. 
option raised in both the Madrid and Zürich Statements. As Cousins and co-authors point out, '[i]t is simply unlikely that society and industry will spend the money and time to generate adequate data to risk assess $>4700{ }^{2}{ }^{21}$

This point is echoed in the Report on PFAS presented to the European Council in 2019, which states: 'In total, 4730 PFAS-related CAS [(Chemical Abstracts Service)] numbers have been identified. A substance-by-substance evaluation of all these substances is therefore not practically possible'. ${ }^{22}$ Similarly, in its recent publication on a chemicals strategy, the Commission remarked:

A fundamental problem of the approach followed until now for PFAS is that it is limited to individual substances or groups of closely related substances. The high number of substances and the lack of information on each specific substance makes it impossible to assess all PFAS substance-by-substance. ${ }^{23}$

In short, there is growing recognition that the risk assessment approach to analyzing PFAS and their alternatives is neither efficient nor practical. Rather than examining each substance individually or as a limited group of substances, Cousins and co-authors propose that the environment and public health would be better served if these substances were to be controlled by categorizing their function and use in society alongside the risk that they may pose. ${ }^{24}$ Such an avenue is a clear departure from the existing approach, which is to begin with technical risk assessment reports to determine threshold dosage levels and then manage any risk through tailored control measures.

\subsection{Essential Use and the Precautionary Approach to Setting Standards}

The genesis of 'essential use' can be traced to the Carter administration's amendments to the Toxic Substances Control Act (TSCA) in $1978,{ }^{25}$ which banned 'non-essential' aerosol sprays, thus affecting nearly USD 3 billion worth of sales in a wide range of products. $^{26}$ Similar actions were taken by Canada, Sweden, ${ }^{27}$ Norway, Denmark, and Finland. ${ }^{28}$ Amendments to the TSCA were introduced at a time when both Congress and the US judiciary ${ }^{29}$ took a precautionary approach towards the regulation of

21 Cousins et al., n. 4 above, p. 1811.

22 Elements for an EU-Strategy on PFAS, n. 7 above, p. 6.

$23 \operatorname{SWD}(2020) 249$, n. 12 above, p. 7.

24 Cousins et al., n. 4 above, p. 1810.

25 Code of Federal Regulations Title 21 (C.F.R. 2.125, 173.345, 189.191, 300.100, 500.49, 700.23, 801.417; 40 C.F.R. 712.1.5, 762.1-.21). The current consolidated version is available at: https://bit.ly/ 346A7X5.

26 For a historic overview of this early environmental legislation in the US and elsewhere see European Commission, 'Proposal for a Council Recommendation on Fluorocarbons in the Environment', 8 Aug. 1977, $\operatorname{COM}(77) 387$, p. 6.

27 'Most Aerosols Face a Swedish Ban', New York Times, 29 Jan. 1978, available at: https://www.nytimes. com/1978/01/30/archives/most-aerosols-face-a-swedish-ban.html.

28 R. Benedick, 'History of the Montreal Protocol', in D. Kaniaru (ed.), The Montreal Protocol, Celebrating 20 Years of Environmental Progress Ozone Layer Climate Protection (Cameron May, 2007), pp. 43-60.

29 Ethyl Corp v. EPA, 598 F.22d 91 (D.C. Cir. 1979) and Reserve Mining Co. v. EPA, 514 F. $2^{\text {nd }} 492$ (8 $^{\text {th }}$ Cir. 1975). In Lead Industry Association Inc v. EPA, 647 F.2d 1130 (D.C. Cir. 1976) the court held (at 
novel, problematic substances. ${ }^{30}$ Later, an essential use exemption was included in the Montreal Protocol. ${ }^{31}$ The justification for including an essential use exemption is analyzed in greater detail below.

The early, precautionary responses to the regulation of hazardous substances adopted a legalistic and qualitative approach to questions regarding the burden of proof, standards of proof and establishment of cause and effect, and were far more inclined to apply a 'zero-tolerance' 32 attitude towards setting safety standards than is currently the case, which applies a threshold dosage approach to ascertaining safety standards. These early views on how to manage hazardous substances are arguably more in tune with incorporating concepts of essential and non-essential use in consumer products than the existing model of risk analysis. The precautionary approach, however, was challenged by producers and industry, particularly in the US. Opponents claimed that a 'zero-tolerance' approach to potentially hazardous substances amounted to 'zero-risk', which was arguably unachievable. ${ }^{33}$

\subsection{Risk Analysis, Thresholds, and Control}

The dispute was eventually settled in 1980 when the US Supreme Court in Benzene 34 held that future standards should be based on threshold measurements. The case was followed three years later by a National Research Council report on managing the process of risk assessment. ${ }^{35}$ Risk analysis is based on quantitative threshold/dosage levels (hazard identification) and risk management through control measures. Beginning with the Reagan administration and with the support of all subsequent administrations, the US has steadily relied on a risk analysis, threshold approach to determining hazardous substances.

It is a form of regulatory oversight which the US has successfully exported through international agreements, most notably the World Trade Organization (WTO) Agreement on the Application of Sanitary and Phytosanitary Measures (SPS Agreement). ${ }^{36}$ Risk analysis also became the favoured approach in the EU with the

1155 ) that the administrator could err on the side of caution. For a good overview of early legislation see S. Jasanoff, Science at the Bar (Harvard University Press, 1997), and J. Zander, The Application of the Precautionary Principle in Practice (Cambridge University Press, 2010), p. 267.

30 See C. Anderson, 'Evolving Conceptions of Science and Legitimacy: Insights from American Administrative Law', in M. Weimer \& A. de Ruijter (eds), Regulating Risks in the European Union: The Co-production of Expert and Executive Power (Hart, 2017), pp. 193-215.

31 Montreal Protocol on Substances that Deplete the Ozone Layer, Montreal, QC (Canada), 26 Aug. 1987, in force 26 Aug. 1989, available at: https://ozone.unep.org/treaties/montreal-protocol.

32 See, e.g., the Delaney Clause on food additives: Federal Food, Drug and Cosmetics Act 1958, 21 U.S.C 348, ss. 408, 409.

33 See J.B. Weiner, 'Precaution in a Multi-Risk World', in D.J. Paustenbach (ed.), Human and Ecological Risk Assessment: Theory and Practice (John Wiley \& Sons Inc., 2002), pp. 1509-31.

34 Industrial Union Department, AFLOCIO v. American Petroleum Institute (Benzene), 448 U.S. 607 (1980).

35 National Research Council, 'Risk Assessment in the Federal Government: Managing the Process' (The National Academies Press, 1983).

36 Marrakesh (Morocco), 15 Apr. 1994, in force 1 Jan. 1995, available at: https://www.wto.org/english/ docs_e/legal_e/15-sps.pdf. 
publication in 2000 of the Commission Communication on the Precautionary Principle. $^{37}$

A further feature of risk regulation as applied in international law, as well as in the US, the EU and other countries, is managing the control of particularly problematic substances by listing them in different types of annex to the statutory instrument seeking to control them. The default position vis-à-vis these select groups of substances is to grant a producer market authorization only if its product features in a positive list typically 'Annex I' of the statutory instrument concerned. Market authorization is typically issued following a thorough risk analysis and control report, and is made subject to a number of conditions, most importantly threshold/dosage levels. The European Commission has identified substances subject to this regime as being ' $a$ priori hazardous'. ${ }^{38}$ In the case of a positive listing, the legislator has 'clearly reversed the burden of proof by requiring that the substances be deemed hazardous until proven otherwise'. ${ }^{39}$ Products containing substances which are considered a priori hazardous include plastic materials coming into contact with food materials, ${ }^{40}$ biocides, ${ }^{41}$ and plant protection products. $^{42}$

Conversely, a large group of chemicals, referred to loosely as 'industrial chemicals' and used in industrial processes and consumer goods, is generally considered safe enough to use. ${ }^{43}$ According to Bergkamp and Abelkop, regulatory authorities around the world list over 100,000 industrial substances, of which about 30,000 are produced at a quantity of at least one metric tonne per manufacturer per year and of which 8,000 are produced in a quantity greater than 11 metric tonnes per year. ${ }^{44}$

Given the huge number of listed industrial chemicals, the general approach to regulating them is to assume that they are safe enough to use, bearing in mind that, as Bergkamp and Abelkop assert, 'the concept of safety is, of course relative. Some chemicals are hazardous to people and eco-systems at low levels of exposure'. ${ }^{45}$ To control substances that are 'safe enough to use' the EU introduced the REACH Regulation. ${ }^{46}$ One of the core features of REACH is that it covers the numerous industrial chemicals

37 European Commission, 'Communication on the Precautionary Principle', COM(2000) 1, 2 Feb. 2000, available at: https://eur-lex.europa.eu/LexUriServ/LexUriServ.do?uri=COM:2000:0001:FIN:EN:PDF.

38 Ibid., p. 20, para. 6.4.

39 Ibid.

40 Regulation (EC) No. 10/2011 on Plastic Materials and Articles Intended to Come into Contact with Food Materials [2011] OJ L 12/1.

41 Regulation (EC) No. 528/2012 concerning the Making Available on the Market and Use of Biocidal Products [2012] OJ L 167/1 (Biocides Regulation).

42 Regulation (EC) No. 1109/2009 concerning the Placing of Plant Protection Products on the Market [2009] OJ L 309/1 (PPP Regulation).

43 L. Bergkamp \& A. Abelkop, 'Regulation of Chemicals', in E. Lees \& J. Viñuales (eds), The Handbook of Comparative Environmental Law (Oxford University Press, 2019), pp. 578-606, at 581.

44 Ibid., p. 581.

45 Ibid., p. 579.

46 Regulation (EC) No. 1907/2006 concerning the Registration, Evaluation, Authorisation and Restriction of Chemicals (REACH), establishing a European ECHA, amending Directive 1999/45/EC and repealing Council Regulation (EEC) No. $793 / 93$ and Commission Regulation (EC) No. 1488/94 as well as Council Directive 76/769/EEC and Commission Directives 91/155/EEC, 93/67/EEC, 93/105/EC and 2000/21/EC [2006] OJ L 396/1 (REACH Regulation). 
in use with the 'no data, no market' rule, the objective of which is to gather as much data on industrial chemicals used and commercialized in Europe. The REACH Regulation further maps the process that enables identification of substances of very high concern (SVHC).

To summarize, the risk analysis and management approach to regulating chemicals in international, US and EU law is to identify a limited number of a priori hazardous substances which require restriction, phasing out, or prohibition. The vast majority of industrial chemicals, on the other hand, are considered 'safe enough' but may still require additional regulatory control, beginning with registration and data collection, and possibly resulting in more stringent regulatory control, particularly if a chemical is classified as an SVHC.

The guiding methodology behind all of these measures is scientific expert evaluation of risk, and consequential risk management. ${ }^{47}$ Given the considerable number of a priori hazardous substances and the sheer volume of existing and new industrial chemicals traded on the global market, some ${ }^{48}$ have described this approach to risk regulation as 'paralysis by analysis'.

\subsection{Expanding on Risk Analysis, towards Categorizing Use and Function}

The criticism that risk regulation encourages paralysis and inefficiency may have been the trigger for the attempt by Cousins and co-authors to revisit the concept of essential use as expressed in the Montreal Protocol on Substances that Deplete the Ozone Layer $^{49}$ and breathe new life into it. A key distinguishing and novel feature of Cousins' regulatory approach to managing hazardous substances is to position regulatory control on the end use of the products in which the substance is commercialized (such as an aerosol spray can) rather than on a threshold dosage approach in the framework of risk analysis. Cousins and co-authors re-examine essential use as set out in the Montreal Protocol, and moreover expand upon its initial parameters by focusing explicitly on the qualitative function and end use of products/substances in society, as opposed to prioritizing risk management as a means to an end alone. In its new iteration by Cousins and co-authors, function and end goods are defined by their societal need and environmental impact, as opposed to just an economic cost-benefit, threshold, risk analysis, risk management, and positive/negative list methodology, as is currently the case.

Significantly - and unlike existing approaches to the regulation of chemicals, which start from the assumption that all industrial chemicals (including, until now, PFAS) are 'safe enough' - the essential use approach assumes that all PFAS are inherently hazardous and should be phased out as a group, rather than individually or substance by substance. The proposed essential use approach towards PFAS in downstream industries would place them into one of three categories: ${ }^{50}$

$47 \operatorname{COM}(2000) 1$, n. 37 above.

48 T. McGarity, 'Some Thoughts on "Deossifying” the Rulemaking Process' (1992) 41(6) Duke Law Journal, pp. 1385-462.

49 Montreal Protocol, n. 31 above.

50 Categorization based on Cousins et al., n. 4 above, pp. 1804-5. 
Category 1 - Non-essential use: ${ }^{51}$ PFAS that are not 'necessary for the betterment of society in terms of health, safety and functioning', which can be phased out by way of a ban or restriction. Non-essential use chemicals are 'nice to have', but society can function without. This would include products such as non-stick frying pans, dental floss, water-repellent surfer shorts, and ski waxes. Even where no alternatives or substitutes exist, Category 1 PFAS can still be banned or phased out because their use is considered non-essential.

Category 2 - Substitutable use: ${ }^{52}$ This covers products that fulfil important functions but are assessed to be non-essential because alternatives are available. What alternatives exist, with time and further analysis, should become better known and the alternatives more easily available, but there is no fundamental obstacle to removing PFAS from products or processes that are currently in use. This could apply, for example, to certain water-resistant textiles for which suitable alternatives to PFAS exist. The 'substitutable use' category, in this context, may work differently from the principle of substitution in REACH, which currently applies a risk analysis and cost-benefit approach to socio-economic requirements (see Section 4.3 below for further detail).

Category 3 - Essential use: ${ }^{53}$ This refers to uses which are considered necessary for health or safety or other highly important purposes for which alternatives are not yet established, such as certain medical devices or occupational clothing.

All in all, based on the analysis given above, this approach appears to be a radical departure from the existing risk analysis approach to granting market approval or authorization.

\section{THE CONCEPT OF 'ESSENTIAL USE' IN INTERNATIONAL ENVIRONMENTAL LAW}

\subsection{The Montreal Protocol on Ozone Depleting Substances}

The 1987 Montreal Protocol and subsequent amendments make up the most important source of 'essential use' in international law. ${ }^{54}$ Following the fourth meeting of the parties in Copenhagen (Denmark) in 1992, an essential use exemption was incorporated into the Montreal Protocol (Decision IV/25). ${ }^{55}$ Minutes of the 1992 meeting indicate why it was felt necessary to introduce this exemption:

Sustainable development, several representatives argued, meant changes in the behaviour of producers and, in particular, of consumers. An example was given, in the context of the Montreal Protocol, that air-conditioning might be an essential use for controlled

51 Ibid., p. 1805.

52 Ibid., p. 1805.

53 Ibid., p. 1805.

54 Montreal Protocol, n. 31 above.

55 Decision IV/25, 'Essential Uses', $4^{\text {th }}$ Meeting of the Parties to the Montreal Protocol on Substances that Deplete the Ozone Layer, UNEP, 23-25 Nov. 1992, available at: https://ozone.unep.org/treaties/montrealprotocol/meetings/fourth-meeting-parties/decisions/decision-iv25-essential-uses?q=fr/meetings/fourthmeeting-parties-montreal-protocol/decisions/decision-iv25-utilisations-essentielles. 
substances in one context and a mere luxury in another. Luxury, and indeed comfort, that entailed damage to the environment would have to be renounced. ${ }^{56}$

Of note in this extract is the emphasis on potentially harmful products destined for consumers that entail both 'luxury' and 'comfort' as examples of 'non-essential use'. This approach, dating back to 1992, echoes the earlier US Carter administration's decision to ban consumer products containing problematic substances, and not just prohibit the problematic substances themselves. It also reflects the sentiment captured in the Category 1 'nice-to-have' products identified and proposed in 2019 by Cousins and co-authors - nearly four decades on from the original intention of non-essential use legislation enacted under the Carter administration and three decades on from the Montreal Protocol, in which essential use is now being used as an exemption to the general prohibition on ozone depleting substances (ODS).

In the end, however, the Montreal Protocol incorporated 'essential use' as a derogation from the prohibition on a priori hazardous ODS $^{57}$ rather than as a tool to categorize the use of the substance in downstream industries, which is the approach preferred by Cousins and co-authors. What is, however, unique to the essential use derogation in the Montreal Protocol is that it recognizes that some hazardous substances are necessary because they are essential not just for the functioning of society, but also for cultural and intellectual reasons.

Decision IV/25 states:

[The use of a controlled ozone-depleting substance] should qualify as 'essential' only if: It is necessary for the health, safety or is critical for the functioning of society (encompassing cultural and intellectual aspects); and

There are no available technically and economically feasible alternatives or substitutes that are acceptable from the standpoint of environment and health. ${ }^{58}$

Since 1992, the essential use derogation for substances that deplete the ozone layer has been extended to include methyl bromide for use in agriculture ${ }^{59}$ but which refers to 'critical' use ${ }^{60}$ and to bromochloromethane. ${ }^{61}$ The Secretariat to the Montreal Protocol regularly prepares a Handbook that lists decisions relating to the essential use exemptions, the most recent edition of which was published in $2020 .^{62}$ The Handbook lists the continued but limited use of problematic ODS in products required

56 Ibid.

57 At present the essential use exemption applies to chlorofluorocarbons (CFCs), halons and other phased out ODS only. Different provisions apply for hydrochlorofluorocarbons (HCFCs) or hydrofluorocarbons (HFCs) with a high global warming potential.

58 Decision IV/25, n. 55 above, para. 1.1. See also UNEP, Ozone Secretariat, Handbook for the Montreal Protocol on Substances that Deplete the Ozone Layer, $14^{\text {th }}$ edn (UNEP, 2020), Section 3.2 'Essential use exemptions', pp. 752-67, available at: https://ozone.unep.org/sites/default/files/Handbooks/MPHandbook-2020-English.pdf.

59 Ibid., Art. 2H, Annex C.

60 Ibid., Section 3.4 'Critical use exemptions for methyl bromide', pp. 768-97.

61 Ibid., Art. 2I, Group III of Annex C.

62 Ibid., pp. 147-304. 
for laboratory and analytical purposes, metred-dose inhalers, for pulmonary diseases, or in very specific aeronautical and space exploration purposes.

\subsection{The Stockholm Convention on Persistent Organic Pollutants}

A similar, though differently phrased example of the essential use derogation can be found in the 2001 Stockholm Convention on Persistent Organic Pollutants (Stockholm Convention). ${ }^{63}$ The Stockholm Convention does not refer to essential use per se. However, its 'specific exemptions' and 'acceptable purposes' derogations with regard to eliminated or restricted substances and products arguably produce a similar effect. ${ }^{64}$ The language of the 'specific exemptions' provisions under the Stockholm Convention is different from that of the essential use exemption in the Montreal Protocol. Under Article 4 of the Stockholm Convention, a party may submit a request to the Convention Secretariat for an exemption for a 'specific reason' 65 or because the substance in question serves an 'acceptable purpose'. ${ }^{6}$

Unlike Decision IV/25 of the Montreal Protocol, which sets out the grounds for an exemption under essential use ('health, safety or is critical for the functioning of society (encompassing cultural and intellectual aspects)'), ${ }^{67}$ Article $4(6)$ of the Stockholm Convention simply states that the party requesting a specific exemption must justify 'its continuing need for registration of that exemption'. Neither the Convention text nor the Convention Secretariat detail the grounds that could be used by a party to justify a specific purpose or acceptable grounds exemption.

\subsection{The Minamata Convention on Mercury}

The 2013 Minamata Convention on Mercury (Mercury Convention) ${ }^{68}$ permits the continued use of certain mercury-containing products on specific grounds, for example,

63 Stockholm (Sweden), 22 May 2001, in force 17 May 2004, available at: http://www.pops.int/ TheConvention/Overview/TextoftheConvention/tabid/2232/Default.aspx. See also P. Sands et al., Principles of International Environmental Law, $4^{\text {th }}$ edn (Cambridge University Press, 2018), p. 583. The purpose of the Stockholm Convention is to protect public health and the environment by imposing measures that reduce or eliminate the production and release of substances considered harmful to both as expressed in Art. 3(1). Annex A of the Stockholm Convention lists those POPs targeted for elimination, while Annex B lists those which are to be restricted. In the case of POPs the number of substances was extended by 14 in 2018 from the original 'dirty dozen' in 2001.

There is limited data or literature on the justification for derogations on the Stockholm Convention website (ibid.).

65 Stockholm Convention, n. 63 above, Annex A 'Substances Targeted for Elimination'. For 'Registers of Specific Exemptions for Chemicals listed in Annex A' see: http:/chm.pops.int/Implementation/ Exemptionsandacceptablepurposes/RegisterofSpecificExemptions/ChemicalslistedinAnnexA/tabid/4643/ Default.aspx.

66 Ibid. Annex B 'Substances Targeted for Restriction'. For 'Registers of Specific Exemptions for Chemicals listed in Annex B' see: http://chm.pops.int/Implementation/Exemptions/SpecificExemptions/ ChemicalslistedinAnnexBRoSE/tabid/5044/Default.aspx.

67 Decision IV/25, n. 55 above, para. 1.1.

68 Kumamoto (Japan), 10 Oct. 2013, in force 16 Aug. 2017, available at: http://www.mercuryconvention. org/Convention/Text. The Mercury Convention seeks to regulate the production and use of mercury. One of the key objectives of this Convention is to phase out and eventually eliminate certain mercury-added products such as batteries, switches, lights, cosmetics, pesticides, and measuring devices. Thus, the Mercury Convention appears to focus more on consumer products and less on the substance itself. 
if they are products 'essential for civil protection and military uses', products for research, measuring devices where no feasible mercury-free replacement is available, products used in traditional or religious practices, and vaccines containing thiomersal as preservatives. $^{69}$

To sum up the first part on how essential use has been utilized in international law, although the 1978 amendments to the TSCA were based partly upon the concept of 'non-essential use' of a consumer product, our research has not identified any international treaties which categorize substances into three distinct profiles as proposed by Cousins and co-authors. However, we have identified protocols and conventions with derogations clauses that use similar language and reflect similar assumptions, such as the notion that the substances being regulated are a priori hazardous, and that their continued use is permitted only as a derogation if it can be seen as either 'essential', 'critical', or justified for an 'acceptable purpose'. On the other hand, the suggestion set out in the minutes of the fourth meeting of the parties to the Montreal Protocol in $1992^{70}$ to exclude the use of hazardous substances in consumer items that offer 'luxury' but are non-essential, appears to have lain dormant in international environmental law, overshadowed by the risk analysis approach favoured by the US after the Benzene decision in 1980.

\section{THE CONCEPT OF ESSENTIAL USE IN EU LAW}

\subsection{Legal Rules regarding Chemical Substances}

The vast majority of EU legal rules that refer to essential use do so in relation to the EU's international commitments under the Montreal Protocol or the Stockholm Convention. For example, Regulation 757/2010 amending Annexes I and III of the Persistent Organic Pollutants Regulation (POPs Regulation) ${ }^{71}$ exempted certain PFOS (used as a fabric stain remover, among other things) and derivatives thereof from the Regulation's provisions if they are needed for an essential use in accordance with provisions of the Stockholm Convention. Similarly, and in line with the need to make EU law consistent with its international obligations under the Stockholm Convention, Regulation 552/2009, amending REACH Annex XVII (Restrictions), states in respect of PFOS that a derogation can be continued for essential uses only if safer alternatives do not exist. ${ }^{72}$

EU implementing decisions do refer to essential use, with the Commission opting to use the term independently from the framework regulation. Other than these very specific exceptions, our research found that the Cousins version of 'essential use' does not form part of the EU legal landscape. It is, however, worth considering whether EU law

69 Mercury Convention, ibid., Annex A.

70 Report of the $4^{\text {th }}$ Meeting of the Parties to the Montreal Protocol, n. 55 above.

71 Commission Regulation (EC) No. 757/2010 amending Regulation (EC) No. 850/2004 on Persistent Organic Pollutants as regards Annexes I and III [2010] OJ L 223/29 (POPs Regulation).

72 Commission Regulation (EC) No. 552/2009 amending Regulation (EC) No. 1907/2006 (REACH Regulation) as regards Annex XVII [2009] OJ L 164/7. 
can accommodate this wider interpretation of the essential use derogation under existing provisions.

\section{REACH}

The overarching piece of secondary legislation affecting the regulation of industrial chemical substances in the EU is the REACH Regulation, ${ }^{73}$ which is based on the internal market provision in Article 114 of the Treaty on the Functioning of the European Union (TFEU). ${ }^{74}$ REACH only mentions 'essential uses' once - namely, in the 2009 amendment regarding PFOS. Other than this one amendment, the market authorization of SVHCs under REACH does not focus on their qualitative, societal, and environmental uses, or distinguish their end use in terms of consumer-oriented 'nice-to-have' use or 'specific-industrial' use.

REACH was finalized in 2006, after the 2000 Commission Communication on the Precautionary Principle, which led EU institutions to agree to consider future use of the precautionary principle in all EU secondary legislation within a managed, formal and structured risk analysis framework. ${ }^{75}$ The managed risk analysis framework is based on the concept of 'reducing the risk' of chemicals as opposed to 'satisfying the essential need of a chemical' in an end product. Risk assessment includes hazard identification, hazard characterization, appraisal of exposure and 'qualitative and/or quantitative estimation ... of the probability, of the frequency and severity of the known or potential adverse environmental or health effects liable to occur'. ${ }^{76} \mathrm{REACH}$ and the accompanying guidance documents prepared by the European Chemicals Agency (ECHA) predominantly use terms such as 'dosage levels', 'concentration', 'threshold levels' and 'risk control'. Prescriptive rules relating to the concept of 'essential use' do not currently form part of REACH governance.

\section{The restrictions procedure}

It could be argued that some of the conditional derogations ${ }^{77}$ with regard to high-risk substances that have been placed on the 'Restrictions List' of the REACH Regulation (Annex XVII) amount to a similar effect as 'essential use'. There are instances where the continued use of otherwise prohibited substances is permitted based on their end use and subject to strict conditionality. In the case of lead sulphates, for example, a conditional derogation exists for Member States who may 'permit the use on their territory

73 N. 46 above.

74 Lisbon (Portugal), 13 Dec. 2007, in force 1 Dec. 2009 [2012] OJ C 326/47, available at: http://eur-lex. europa.eu/LexUriServ/LexUriServ.do?uri=OJ:C:2012:326:FULL:EN:PDF.

$75 \operatorname{COM}(2000) 1, \mathrm{n} .37$ above, at bullet point 4 of the summary: 'The precautionary principle should be considered within a structured approach to the analysis of risk which comprises three elements: risk assessment, risk management, risk communication. The precautionary principle is particularly relevant to the management of risk'.

76 Ibid., Annex III, p. 28.

77 European Chemicals Agency, 'Guidance for the Preparation of an Annex XV Dossier for Restrictions', June 2007, available at: https:/echa.europa.eu/documents/10162/23036412/restriction_en.pdf/ d48a00bf-cd8d-4575-8acc-c1bbe9f9c3f6. 
of the substance or mixture for the restoration and maintenance of works of art and historic buildings and their interiors, as well as the placing on the market for such use'.78

These, however, are the exceptions to the norm. Most conditional derogations listed in Annex XVII reference threshold limits for controlled substances - such as '[s] hall not be placed on the market, or used, as substances or in mixtures in concentrations greater than $0,1 \%$ by weight ${ }^{79}$ - as opposed to end-use conditionality based on their function in society.

Furthermore, the restriction procedure applies largely to substances which a public authority, Member State or the ECHA has identified as involving an 'unacceptable risk to human health or the environment' ${ }^{80}$ In the case of PFAS, the Commission has initiated two studies the purpose of which is to examine the hazardous nature of PFAS in fire-fighting foam and textiles. ${ }^{81}$ Given the mounting scientific consensus on the hazardous nature of PFAS and their substitutes, ${ }^{82}$ it is likely that scientific expertise will allow a relatively quick determination that PFAS do indeed pose an unacceptable risk to human health and the environment. ${ }^{83}$ It is not yet clear, however, whether all 4,700 PFAS could fall under a restrictions procedure.

The task is no doubt complicated by the fact that polymers (which include a large number of PFAS) so far have been largely exempted from the REACH registration provisions. For this reason the European Commission's 2020 Chemicals Strategy proposes that all PFAS should be classified as a group as a matter of urgency. ${ }^{84}$ Despite potential complications in relation to phasing out 4,700 PFAS following a restrictions procedure, the Commission is confident that this is the best route for phasing out PFAS:

The chemicals legislation (REACH) has a very effective tool to manage the risk from substances, such as PFAS, that are used in industrial processes but also in products: the restriction. A restriction can ban the manufacture, placing on the market or use of a chemical substance, or a group of substances. It applies also to imported products and it is flexible, because it can include derogations, unlimited in time or time limited. A REACH restriction is an appropriate EU instrument to address PFAS concerns at the source. ${ }^{85}$

As the Commission notes, however, the restriction procedure is a 'very effective tool to manage the risk' (emphasis added). It cannot be said - yet - that the restrictions

78 Commission Regulation (EU) No. 126/2013 amending Annex XVII to Regulation (EC) No. 1907/2006 on the Registration, Evaluation, Authorisation and Restriction of Chemicals (REACH) [2013] OJ L 43/24, Annex XVII, Points 16-17. The lead carbonates and sulphates concerned are PbSO4, CAS No. 7446-14-2, EC No. 231-198-9 and Pbx SO4, CAS No. 15739-80-7, EC No. 239-831-0.

79 Commission Regulation (EC) No. 552/2009, n. 72 above, Annex XVII, Points 12-15.

80 REACH Regulation, n. 46 above, Art. 68(1).

$81 \operatorname{SWD}(2020) 249$, n. 12 above, p. 10. According to the Commission, fire-fighting foams and textiles are among the uses with the largest PFAS emissions to the environment.

82 Ibid. See also G. Goldenman et al., The Cost of Inaction: A Socioeconomic Analysis of Environmental and Health Impacts Linked to Exposure to PFAS (Nordic Council of Ministers, 2019), available at: http://norden.diva-portal.org/smash/get/diva2:1295959/FULLTEXT01.pdf.

83 Ibid.

$84 \operatorname{COM}(2020) 667$, n. 9 above, p. 13.

$85 \operatorname{SWD}(2020) 249$, n. 12 above, p. 10. 
procedure is a very effective tool to manage non-essential and essential use as a means to phase out PFAS.

\section{Downstream industries, health and environmental legislation}

Beyond REACH, the concept of categorizing PFAS into three separate use-based categories similarly does not seem to feature in secondary legislation which affects the chemical management of downstream industries that produce PFAS-containing products. These include the pharmaceutical, veterinary, textile, plant, food additives, and food packaging industries. This set of secondary legislation displays varying provisions, requirements, risk management schemes, and exceptions. This is because, to date, the EU has chosen to regulate these industries sector by sector rather than holistically. Annex 4 of the Commission's Staff Working Document ${ }^{86}$ on the fitness check of the most relevant chemicals legislation (excluding REACH) lists over 40 pieces of legislation that are affected by chemical hazard and risk assessments, risk management requirements, procedures and processes. Regulated products include cosmetics, toys, detergents, fertilizers, food contact materials, plant protection products, and biocides, all of which could fall within the proposed essential use concept if their products contain PFAS.

In addition to these sector-specific pieces of legislation, EU directives such as the Industrial Emissions Directive, ${ }^{87}$ the Water Framework Directive, ${ }^{88}$ the Groundwater Directive, ${ }^{89}$ the Habitats Directive, ${ }^{90}$ and the Directive on the Sustainable Use of Pesticides $^{91}$ also contain measures to protect the environment from chemical substances. Finally, the EU seeks to protect workers and vulnerable groups from hazardous chemicals through occupational health and safety legislation..$^{92}$ None of the EU legislation setting out prescriptive rules on chemical substance regulation - whether concerning sector-specific issues, health and safety at work, or environmental issues includes an essential use concept as described by Cousins and co-authors. ${ }^{93}$

86 SWD(2019) 199, Commission Staff Working Document, 'Fitness Check of the Most Relevant Chemicals Legislation (excluding REACH), as well as Related Aspects of Legislation Applied to Downstream Industries', 25 Jun. 2019, available at: https://data.consilium.europa.eu/doc/document/ST-107052019-ADD-2/en/pdf.

87 Directive 2010/75/EU on Industrial Emissions (Integrated Pollution Prevention and Control) [2010] OJ L 334/17.

88 Directive 2000/60/EC establishing a Framework for Community Action in the Field of Water Policy [2000] OJ L 327/1 (Water Framework Directive).

89 Directive 2006/118/EC on the Protection of Groundwater against Pollution and Deterioration [2006] OJ L 372/19.

90 Council Directive 92/43/EEC on the Conservation of Natural Habitats and of Wild Fauna and Flora [1992] OJ L 206/7.

91 Directive 2009/128/EC establishing a Framework for Community Action to Achieve the Sustainable Use of Pesticides [2009] OJ L 309/71.

92 Directive 89/391/EEC on the Introduction of Measures to Encourage Improvements in the Safety of Health of Workers [1989] OJ L 183/1; Directive 98/24/EC on the Protection of the Health and Safety of Workers from the Risks related to Chemical Agents at Work [1998] OJ L 131/11.

93 There is an echo of essential use in Directive 2002/95/EC on the Restriction of the Use of Certain Hazardous Substances in Electrical and Electronic Equipment [2003] OJ L 37/19 (RoHS). Art. 5(1)(b) instructs the follow-up and potential amendment of the Annexes to the Regulation, aimed at exempting materials and components of electrical and electronic equipment from the obligation of Art. 4(1) to 


\subsection{Case Law of the Court of Justice of the European Union on Essential Use}

The European Commission has employed essential use as a tool to permit certain substances to be marketed and authorized within the EU. In two Commission implementing decisions ${ }^{94}$ relating to (now repealed) Directive 91/414/EC concerning the Placing of Plant Protection Products on the Market, ${ }^{95}$ the European Commission decided that the active substances simazine and atrazine no longer met the environmental requirements of the Directive, but that under conditions of strict monitoring their continued use should be allowed. It did so in both cases with reference to essential use.

The wording used in Commission Decision 2004/247, concerning the use of simazine, is of interest in the context of this article. The Commission found that simazine has the potential to contaminate groundwater at higher concentrations, and withdrew its market authorization. However, Recital 12 of the implementing decision recognized that it is:

justified in the present circumstances to prescribe under strict conditions aimed at minimising risk a longer period for the withdrawal of existing authorisations for the limited uses [of simazine] considered as essential for which no efficient alternatives appear currently to be available for the control of harmful organisms. ${ }^{96}$

Two environmental organizations contested the continued use of simazine. In EEB and Stichting Natuur \& Milieu v. Commission, ${ }^{97}$ the applicants sought annulment of specific parts of the two decisions - namely, the obligation on behalf of the Member States to ensure that alternative products are being seriously sought, and the inclusion of a sunset clause on the grace period. The Court of Justice of the European Union (CJEU) unfortunately did not rule on the substance of the case as the parties were found not to have standing. ${ }^{98}$

One year later, a similar implementing decision concerning plant protection products (this time aldicarb) was contested, and this time the CJEU did consider the substantive issue around essential use. In Stichting Zuid-Hollandse Milieufederatie v. College voor de Toelating van Bestrijdingsmiddelen ${ }^{99}$ a Dutch national court held

replace lead, mercury, cadmium, hexavalent chromium, polybrominated biphenyls (PBB) or polybrominated diphenyl ethers (PBDE), if their elimination or substitution via design changes or materials and components which do not require any of the materials or substances referred to therein is technically or scientifically impracticable, or where the negative environmental, health and/or consumer safety impacts caused by substitution are likely to outweigh the environmental, health and/or consumer safety benefits thereof. This last element clearly is not quite the same as essential use (environment, health and consumer safety being a narrower category); however, the sentiment of this provision goes some way towards that of essential use.

94 Commission Decision 2004/247/EC concerning the Non-Inclusion of Simazine in Annex I to Council Directive 91/414/EEC and the Withdrawal of Authorisations for Plant Protection Products Containing this Active Substance [2004] OJ L 78/50; Decision 2004/248/EC held essentially the same for atrazine [2004] OJ L 78/53.

95 Council Directive 91/414/EEC concerning the Placing of Plant Protection Products on the Market [1991] OJ L 230/1.

96 Commission Decision 2004/247, n. 94 above, recital 12.

97 Joined Cases T-236/04 and 241/04, EEB v. Syngenta Crop Protection, ECLI:EU:T:2005:426.

98 Ibid., para. 73.

99 Case C-174/05, Stichting Zuid-Hollandse Milieufederatie and Stichting Natuur en Milieu v. College voor de toelating van bestrijdingsmiddelen, ECLI:EU:C:2006:170. 
that the Commission decision on aldicarb ${ }^{100}$ was illegal. It reasoned that if the environmental conditions of the Directive cannot be met then the substance cannot be authorized under any circumstances. Consequently, the Dutch court had to refer the question to the CJEU, as only the CJEU may declare an EU act illegal.

The CJEU disagreed with the national court, holding that the EU institutions had properly prepared and had found a balance between the internal market and the environmental objectives of the Directive. ${ }^{101}$ It then sanctioned the deployment of essential use:

[T] he establishing of different time limits for the withdrawal of authorisations to place on the market plant protection products containing the active substance 'aldicarb' on the basis of the use which is made of those products, the restricted nature of the list of essential uses, the application of that exception to only some Member States and the subjection of those uses to a stringent follow-up and monitoring programme, in accordance with the tenth recital in the preamble to Decision 2003/199, are all factors which show that the Council carried out a global assessment of the advantages and drawbacks of the system to be established and that that system was not on any view manifestly inappropriate in the light of the objectives pursued. ${ }^{102}$

The CJEU thus justified the Commission's decision to exempt aldicarb from a complete ban. As far as we are aware, however, Bayer CropScience (producer of aldicarb) never had to produce a report justifying why the use of aldicarb is essential or 'necessary for the health, safety or is critical for the functioning of society (encompassing cultural and intellectual aspects)'. 103

Again, we see the CJEU upholding the risk analysis approach to the governance of substances (in this case aldicarb) as opposed to applying the concept of essential use as proposed by Cousins and co-authors. The reasoning of the CJEU is very much in line with the main yardsticks of a risk analysis approach - namely, control, threshold limits, and safety. Cousins' approach, on the other hand, would consider the potential uses of aldicarb and determine whether to authorize depending on whether such use would be considered (i) non-essential, (ii) substitutable, or (iii) essential. Therefore, the decision whether to authorize continued use of aldicarb would depend not on its hazardous properties, risk reduction and control measures alone, but rather on how the substance functions in a given product, and on the potential value of this product for the functioning of society.

The Cousins approach does not necessarily lead to complete prohibitions or restrictions. The end result of an essential use approach for a substance such as aldicarb may be similar to that under the existing model - that is, being permitted in small quantities under highly controlled circumstances. The steps in arriving at that conclusion, however, are a fairly radical departure from risk analysis. There is little doubt that even

100 Council Decision 2003/199/EC concerning the Non-Inclusion of Aldicarb in Annex I to Council Directive 91/414/EEC and the Withdrawal of Authorisations for Plant Protection Products Containing this Active Substance [2003] OJ L 76/21.

101 Case C-174/05, n. 99 above, para. 30.

102 Ibid., para. 32.

${ }^{103}$ Decision IV/25, n. 55 above, para. 1.1. 
under the essential use approach, technical reports and risk analysis would play a vital role in future regulation, but they might no longer be the starting point of regulatory analysis.

\subsection{Legal Principles for Chemical Substances}

Over the past 40 years, the EU has increasingly adopted a number of cross-sector principles that apply to the chemical sector. The most pertinent environmental principles affecting this sector are precaution, prevention, polluter pays, and the principle of substitution. For the purposes of this article, the precautionary principle and the principle of substitution are the most relevant.

\section{The precautionary principle}

The precautionary principle lacks a general (as opposed to sectoral) definition. As a result, the application of the principle varies across secondary legislation affecting the chemical sector. For example, most if not all of the aforementioned 40 pieces of secondary legislation listed in Annex 4 of the Commission Staff Working Document on the most relevant chemicals-related legislation (excluding REACH) refer to the precautionary principle either directly or indirectly. The principle is either loosely referred to in the recitals ${ }^{104}$ or more indirectly as a harm-related reference in an Article. ${ }^{105}$ In some cases the principle is not directly mentioned but can be inferred by reference to risk assessment and risk management provisions. ${ }^{106}$

In the absence of a general definition of the precautionary principle in either primary or secondary EU law pertaining to chemicals ${ }^{107}$ the 2000 Commission Communication on the Precautionary Principle ${ }^{108}$ remains the go-to document for both legislative and judicial interpretation. One of the core features introduced by the publication of the Communication was precaution via risk analysis and management, with a focus on hazard identification, dosage and threshold levels determined by independent expert evaluation. This new approach to implementing the precautionary principle is very much reflected in post-2000 EU secondary legislation on the control and management of hazardous substances, including chemicals.

104 Directive 2008/56/EC establishing a Framework for Community Action in the Field of Marine Environmental Policy (Marine Strategy Framework Directive) [2008] OJ L 164/19, recitals 27, 24; Directive 2000/60/EC establishing a Framework for Community Action in the Field of Water Policy [2000] OJ L 327 (Water Framework Directive), recitals 11, 44.

105 Directive 2010/75/EU on Industrial Emissions (Integrated Pollution Prevention and Control) (IED Directive) [2010] OJ L 334/17, Arts 52, 59.

106 Directive 2008/50/EC on Ambient Air Quality and Cleaner Air for Europe [2008] L 152/1.

107 The only piece of EU secondary legislation which defines the precautionary principle is Art. 7 of Regulation (EC) 178/2002 No. 178/2002 laying down the General Principles and Requirements of Food Law, establishing the European Food Safety Authority and laying down Procedures in Matters of Food Safety [2002] OJ L 31/1 (General Food Safety Regulation).

$108 \operatorname{COM}(2000)$ 1, n. 37 above. For an overview of relevant scholarship see E. Vos \& K. De Smedt (eds), 'Taking Stock as a Basis for the Effect of the Precautionary Principle since 2000', RECIPES Project, Feb 2020, available at: https://recipes-project.eu/sites/default/files/2020-03/Report\%20Taking\%20stock $\% 20$ as $\% 20$ a $\% 20$ basis $\% 20$ for $\% 20$ the $\% 20$ effect $\% 20$ of $\% 20$ the $\% 20$ precautionary $\% 20$ principle $\% 20$ since $\% 202000$.pdf. 
The decision to place the precautionary principle at the very heart of a structured risk framework resulted in chemicals being regulated according to the risk they may or may not pose, rather than any residual doubt regarding their safety. The risk analysis approach assumes that in the vast majority of cases chemicals are safe, depending on the dosage. In cases where safety levels cannot be defined, the chemical must be restricted, but even in this case miniscule amounts may be permitted following an evaluation procedure and the submission of a restrictions dossier. Within this approach social concerns are certainly considered, but they appear to play a less central role than analytical, quantifiable risk assessment and cost-benefit analysis.

REACH includes provisions for a 'socio-economic report' but while its Annex XVI on 'Socio-Economic Analysis' (SEA) enumerates a number of societal issues that must be taken into account (including social and economic benefits of the proposed restriction on worker health, environmental performance, and the distribution of these benefits in terms of geography and population groups), they appear to be somewhat overshadowed by the high number of economic criteria. ${ }^{109}$ The criteria set out in the SEA are arguably more in tune with an analytical, quantifiable and economic risk costbenefit analysis than a more qualitative environmental or essential use test. ${ }^{110}$

On the other hand, an essential use approach to the regulation of PFAS, such as defined in the Montreal Protocol and Decision IV/25, ${ }^{111}$ includes more complex, qualitative (as opposed to quantitative), and social considerations. An essential use is not necessarily the same as an economic use. The use of the phrase 'necessary for the health, safety or is critical for the functioning of society (encompassing cultural and intellectual aspects) ${ }^{, 112}$ already puts it on a different level from the analytical cost-benefit study prescribed in Annex XVI of the socio-economic report.

Social considerations often require value-driven evaluations based on common normative perceptions which, unlike a scientific risk assessment or an economic costbenefit analysis, cannot easily be quantified or objectively assessed by a regulator. For example, from a normative value-driven point of view, it could be argued that a PFAS substance in a frying pan is not essential for the technical functioning of the product, let alone essential for the health, safety, or functioning of European society, but there is no quantifiable, calculable index that can determine the validity of this

109 Including the impact on industry (e.g., manufacturers and importers); all other actors in the supply chain, downstream users, and associated businesses in terms of commercial consequences, such as impact on investment, research and development, innovation, one-off and operating costs (e.g., compliance, transitional arrangements, changes to existing processes, reporting and monitoring systems, installation of new technology, etc.), taking into account general trends in the market and technology, product prices, changes in composition or quality or performance of products, availability of products, consumer choice; wider implications on trade, competition and economic development (in particular, for small to mediumsized enterprises and in relation to third countries).

110 For a distinction between a cost-benefit analysis as specified by risk approaches and a comparison with the EU principle of proportionality, see Zander, n. 29 above, pp. 21-22, 98-99.

111 It is worth noting that the Montreal Protocol (n. 31 above) does not mention risk once in the $202014^{\text {th }}$ edition of its Handbook (n. 58 above), nor does the essential use amendment in Decision IV/25 (n. 55 above).

112 Decision IV/25, ibid., para. 1.1. 
assumption. Rather, regulators are asked to rely on their judgement - not a rigid, utilitarian, tick-box exercise of calculable economic and societal measurements.

The concept of essential and non-essential use, therefore, represents a clear shift away from the current emphasis of the precautionary principle on robust, objective scientific evaluation. Instead, it shifts decision making towards a more value-driven, normative, and socio-economic approach.

\section{The principle of substitution}

The principle of substitution is less well known than the precautionary principle. However, its adoption in the chemicals sector is widespread and crucial, covering not just the REACH Regulation but also the Biocides Regulation, ${ }^{113}$ the PPP Regulation, ${ }^{114}$ as well as numerous other pieces of EU secondary legislation dealing with worker health and safety and environmental considerations, such as the Habitats Directive ${ }^{115}$ and the Natura 2000 programme. $^{116}$ The principle of substitution is also relevant to this article because under the new approach proposed by Cousins and co-authors, substitution plays a crucial role in the regulation of PFAS. However, the essential use approach to the regulation of substitutes is somewhat different from the approach currently adopted under REACH and related chemicals legislation.

The principle of substitution has been defined as follows: 'If an existing activity is found to be harmful it is a candidate for being replaced by a more benign option'. ${ }^{117}$ Although, arguably, not yet considered a general principle of EU environmental law, we nevertheless see that substitution (or 'alternative use' as it is sometimes called) has been adopted in a number of statutory instruments both in the EU and the US. ${ }^{118}$ Substitution forms a core part of REACH and it is referenced repeatedly throughout the Regulation and its recitals. ${ }^{119}$

However, as the Cousins paper highlights, substitutes - particularly PFAS substitutes - are not always 'benign', many posing similar risks to those of the grandfathered, hazardous substances. ${ }^{120}$ A second concern with the principle of substitution is the requirement that SVHCs are replaced with alternatives 'where these are economically and

\footnotetext{
113 N. 41 above.

114 N. 42 above, Arts 22, 47.

115 N. 90 above.

116 European Commission, 'Natura 2000', available at: https://ec.europa.eu/environment/nature/natura2000/ index_en.htm.

117 G. Winter, 'Substitution: From Alternatives to Ecological Proportionality', in L. Krämer \& E. Orlando (eds), Principles of Environmental Law (Edward Elgar, 2018), pp. 234-50, at 248ff.

118 Ibid., p. 235.

119 See, e.g., REACH Regulation, n. 46 above, Art. 55 (which specifies that '... risks from substances of very high concern [SVHC] are properly controlled and that these substances are progressively replaced by suitable alternative substances or technologies where these are economically and technically viable'). Any operator looking to place on the market or continue to use an Annex XIV (SVHC) substance must seek authorization to do so. Art. 62(4) requires the operator to submit an analysis of the alternatives and show what suitable alternatives are available.

120 See, e.g., S. Gold \& W. Wagner, 'Filling Gaps in Science Exposes Gaps in Chemical Regulation' (2020) 368(6495) Science, pp. 1066-8.
} 
technically viable', ${ }^{121}$ and Article 60(4) REACH Annex XIV, which permits the continued use of certain substances 'if it is shown that socio-economic benefits outweigh the risk to human health or the environment arising from the use of the substance and if there are no suitable alternative substances or technologies' ${ }^{122}$ Thus, if no suitable 'technical and economic ${ }^{, 123}$ alternative (objective, technical criteria) exists, the substance may still qualify for market authorization if it can be shown that 'socio-economic benefits outweigh the risk to human health or the environment ${ }^{124}$ (or, in accordance with a socioeconomic cost-benefit analysis). As we argued above (in the section on the precautionary principle), the socio-economic report is tilted heavily in favour of an economic analysis, which is easier to quantify than a social function. Winter gives an example, extracted from the ECHA website, of the existing approach to substitution:

ZF Luftfahrttechnik GmBH applied for the authorisation of the carcinogenic and reprotoxic substance sodium dichromate for surface treatment of certain metals. An analysis of the alternatives concluded that the potential alternatives 'do not support all the properties of chromate-based surface treatment systems, and their long-term performance can currently only be estimated. Decreased corrosion protection would necessitate shorter inspection intervals, with a substantial impact on associated maintenance costs' (ECHA, Analysis of Alternative). ${ }^{125}$

In the case of sodium dichromate, it is easier to quantify what might be lost if it were restricted or banned completely. How to regulate the same substance in terms of its essential use may be harder to quantify and measure.

\section{Comparing substitution in essential use with substitution in REACH}

The Cousins categorization into three very specific uses differs from existing applications of the substitution principle in most statutory instruments concerning chemical substances, including REACH. Firstly, Cousins' 'essential use' concept creates 'three categories of uses' of which 'substitution' is just one, and according to their proposed schematic arrangement, substitution should be relied upon once all 'nice-to-have' but 'non-essential' uses have been eliminated. ${ }^{126}$ Thus, unlike the existing application of substitution in REACH, the principle of substitution would play not a primary but a secondary role in the regulation of PFAS.

Secondly, Cousins and co-authors propose:

When considering chemical alternatives for PFAS, the focus should be on the service the product should deliver. The compound should therefore be evaluated for performance using the specifications required for the products, as opposed to comparing directly to

121 REACH Regulation, n. 46 above, Art. 55.

122 Ibid., Art. 60(4).

123 Ibid., Art. 62(4).

124 Ibid.

125 Winter, n. 117 above, p. 242.

126 We tentatively speculate that 'the-first-to-go' non-essential products would be consumer goods where the continued use of PFAS may confer 'luxury' or 'comfort', but which are harmful to public health and the environment. 
the PFAS being replaced ... additional considerations such as product longevity, persistence in the environment, and sustainability may be considered. ${ }^{127}$

Contrast this with the existing approach to substitution, which compares one substance with another and which still allows authorization for use if no suitable 'economically and technically viable' alternative is available. The essential use concept of substitution is therefore broader, incorporating a wider analysis which must include environmental considerations - such as product longevity, persistence in the environment, and sustainable use - and not just the technical and economic impact of prohibiting a hazardous substance.

Thirdly, the concept of essential use forces regulators to assess not just the substance but also the end products and what purpose(s) they serve.

The differences between substitution as relied upon in REACH and Category 2 'substitutable uses' can best be illustrated when applying Cousins' categorization method to the aforementioned example of sodium dichromate (supposing it were a PFAS). Rather than just considering whether a suitable economically and technically viable alternative to sodium dichromate exists (which would be the current procedure under REACH), market authorization assessment for sodium dichromate would proceed as follows:

Step 1 - Non-essential use: Is sodium dichromate 'nice to have' but not essential for the functioning of society? Would it be useful to have this problematic substance in all downstream industries where the substance does not serve a useful function in society - regardless of the dosage - such as in a toy aeroplane, a garden spade or an outdoor dining table? For this category of products the use of this substance may be non-essential, in which case its continued use in these products would be phased out or banned. We assume this covers most, if not all, consumer products. If, on the other hand, the ECHA deemed that sodium dichromate serves an important function for the surface treatment of a particular specialized industry, such as the aeronautical sector, then the analysis would move to Step 2.

Step 2 - Substitutable use: What suitable alternatives to sodium dichromate are available? It is important to note that under this approach substitutes are not regarded as benign per se; rather, there may simply be no alternative. This evaluation may compare the existing substance's longevity, persistence in the environment, and sustainability with that of the potential substitute. The cost-benefit analysis should take into account not only the technical function and economic value of the substitute but also the persistence of the substitute in the environment and its sustainability in the long term. The alternative thus needs to be not only 'economically and technically viable' but also 'environmentally viable'.

Step 3 - Essential use: If no suitable alternative exists and the use of sodium dichromate is deemed essential for the safety and proper functioning of surface metals in the aeronautical industry, sodium dichromate could be classified as essential and its continued use permitted within the aeronantical sector only until a suitable, more benign alternative became available.

127 Cousins et al., n. 4 above, p. 1810. 
In fact, sodium dichromate is used in the aeronautical sector for a very specific purpose and is not common in everyday consumer goods. This already sets it apart from non-essential but 'nice-to-have' applications and makes its continued use likely in the absence of a suitable environmental alternative. The novelty of Cousins' approach is that it forces regulators to consider a whole category of goods, services and processes in a new light, effectively distinguishing between consumer goods and goods which serve a very specific purpose. Thus, sodium dichromate may serve a useful, necessary, and specific function within the aeronautical sector for which no alternatives currently exist, but its use in toy aeroplanes is clearly non-essential and, given its hazardous nature, should be phased out as soon as possible. In short, the essential use approach goes beyond analyzing the risk and economic cost-benefits to alternatives and towards incorporating environmental concerns.

At the fourth meeting of the Montreal Protocol, when the principle of essential use was first introduced, the parties noted the difference between the use of hazardous substances in consumer products which are deemed a mere luxury, and other products which serve a specific purpose. Cousins' proposal for the regulation of PFAS as a group and categorizing them under three headings is a return to this early approach of distinguishing between different categories of products and the purposes they serve, rather than over-emphasizing the quantitative risk analysis of substances and the economic, technical cost-benefit analysis of alternatives.

Furthermore, Cousins' approach does recognize that 'grey zones' will open up between the three categories of use, which should be better defined. However, the purpose of essential use, according to the authors, is to try and avoid 'regrettable substitution', which is similar to the 'old' substance but which is potentially as equally problematic as the preceding one. ${ }^{128}$

As far as socio-economic factors are concerned, sources within the non-governmental organization sector, while recognizing the challenge of defining function within society, currently consider them under-evaluated within the parameters of the principle of substitution:

Right now, there is no organisation that has the mandate to say 'this is not really a function we need as a society'. This has been obvious to us, for example, in the discussion for the $\mathrm{REACH}$ authorisation process, where alternatives to the most hazardous chemicals are not seen as feasible if they do not provide the exact same aesthetic quality. ${ }^{129}$

Were Cousins' proposal to be adopted as a new approach to the regulation of PFAS, 'aesthetic quality' alone might be deemed 'nice-to-have but non-essential'.

\subsection{Conclusion on the Status Quo of the Concept of 'Essential Use' in International, EU and Member State Chemical Substances Legislation}

From our research we have been able to ascertain that chemicals-related treaties and EU legislation apply 'essential use' in a limited manner, and where they do so it is used as a

128 Ibid., p. 1810.

129 A. Turley, 'Exempt "Essential Uses" to Accelerate PFAS Phaseout, Experts Say', Chemical Watch, 20 June 2019, available at: https://chemicalwatch.com/78942/exempt-essential-uses-to-acceleratepfas-phaseout-experts-say. 
derogation from a priori hazardous substances. Although reference to essential use does appear in EU secondary legislation, it appears in a form which does not resemble that proposed by Cousins and co-authors. Ever since the adoption of the Commission Communication on the Precautionary Principle in 2000, the EU has prioritized the establishment of a structured and managed risk analysis framework which is reflected in chemicals-related legislation, notably REACH as well as the numerous sectoral pieces of secondary legislation that affect downstream industries.

\section{ADOPTING THE CONCEPT OF ESSENTIAL USE}

Having established that the concept of essential use is not currently part of the standard EU or international regulatory toolkit for the regulation of hazardous substances such as PFAS, this section offers preliminary insight into whether and how EU law could accommodate the concept.

The Commission recently published its 2020 Chemicals Strategy for Sustainability, which actively seeks to incorporate the concept of essential use as a key tool towards achieving a toxic-free Europe. ${ }^{130}$ This document, however, is vague on detail other than recognizing the need to 'define criteria for essential use, taking into account the definition of the Montreal Protocol'. ${ }^{131}$ In particular, there is no detail on how exactly the Commission intends to define the criteria.

More specifically with regard to PFAS, the Commission proposes to phase them out via the REACH restrictions procedure by submitting a proposal to restrict all nonessential uses, including in consumer products, via the comitology procedure (which means intermediate adjustments to EU law via delegation jointly exercised by the Commission and the Member States). ${ }^{132}$ Given the mounting evidence of harm from PFAS and growing public opposition to these substances, it is likely that the Commission will push through a phase-out of PFAS through the comitology method (essentially an administrative follow-up of existing legislation). However, comitology and the restrictions procedure are arguably insufficiently robust, in the long-term, as an implementation of the concept of essential use. Relying too heavily on comitology and a restrictions procedure renders the concept of essential use vulnerable to judicial review, and to the charge that the Commission is overreaching its authority.

In addition to comitology and the restrictions procedure, the EU could incorporate the concept of essential use into the corpus of EU law in three further ways: firstly, by applying the safeguard clause under Article 129 REACH or the environmental guarantee of Article 114 TFEU; secondly, by amending existing regulation and stating explicitly that essential use will be used as part of the decision-making process; thirdly, by gradually introducing the concept of essential use as a principle in EU law.

\footnotetext{
${ }^{130} \operatorname{COM}(2020) 667$, n. 9 above.

131 Ibid., p. 2.

132 Ibid., p. 3.
} 


\subsection{Use of Safeguard Clauses}

The use of safeguard clauses, in our view, is the least effective way to incorporate the concept of essential use. There is currently no possibility de lege lata to support a phaseout via a prohibition or restriction of PFAS either by applying the three categories proposed by Cousins and co-authors (non-essential use, substitutable use, and essential use) or on the basis that they are not 'necessary for the betterment of society in terms of health, safety and functioning'. ${ }^{133}$ One of the biggest limitations of the safeguard approach is the decision to apply a risk management method to the regulation of hazardous substances post 2000, and the subsequent framing of EU law to provide scientific evidence of harm as opposed to societal choices in terms of function.

\section{Article 129 REACH: safeguard clause}

A Member State could potentially utilize the concept of essential use via the safeguard clause set out in Article $129 \mathrm{REACH} .{ }^{134}$ Under certain conditions a Member State may trigger the safeguard clause and take appropriate provisional, derogating measures if it has justifiable grounds for believing that urgent action is essential to protect human health or the environment in respect of a substance, on its own, in a mixture, or in an article, 'even if satisfying the requirements of this Regulation' ${ }^{135}$ This clause was invoked in the case of the approved ban (total restriction) by France in 2013 on cellulose wadding insulation materials containing ammonium salts adjuvants. ${ }^{136}$ This was the first and, to our knowledge, the only time that the safeguard clause has been successfully applied. To use the safeguard clause, the Member State concerned must prepare a REACH Annex XV dossier to initiate an EU restrictions procedure within three months of the Commission's Decision confirming the provisional national measure (Article 129(3) REACH). ${ }^{137}$ Once again, however, the initiative must carry out the exact same Annex XV requirements, which do not include an essential use approach.

\section{Article 114 TFEU: safeguard measures}

A further possibility for a Member State to take unilateral action is contained in the environmental guarantee of Article $114(3)$ and (4) TFEU. ${ }^{138} \mathrm{REACH}$ is a market

133 Cousins et al., n. 4 above, p. 1810.

134 REACH Regulation, n. 46 above, Art. 129.

135 Ibid., Art. 129(1). Another option would be to rely on Art. 114(5) TFEU if new scientific evidence on the environmental impact, which is specific to that Member State and has arisen after the adoption of the EU harmonized measure, can support the national measure. The adoption by Member States of conditions other than those under REACH is incompatible with the objectives of REACH; see Joined Cases C-281/03 \& 282/03, Cindu Chemicals and Others, ECLI:EU:C:2005:549, para. 44; and Case C-358/11, Lapin elinkeino-, liikenne- ja ympäristökeskuksen liikenne ja infrastruktuuri -vastuualue v. Lapin luonnonsuojelupiiri ry, ECLI:EU:C:2013:142, para. 37.

136 Commission Implementing Decision 2013/505/EU authorising the Provisional Measure taken by the French Republic in accordance with Article 129 of Regulation (EC) No. 1907/2006 concerning the Registration, Evaluation, Authorisation and Restriction of Chemicals (REACH) to Restrict the Use of Ammonium Salts in Cellulose Wadding Insulation Materials [2013] OJ L 275/52; and Commission Implementing Decision 2015/1131/EU amending Implementing Decision 2013/505/EU [2015] OJ L 184/20.

137 REACH Regulation, n. 46 above, Art. 129(3).

138 Art. 114 TFEU. 
harmonization instrument based on Article 114 TFEU and not an environmental measure based on Article 193 TFEU, ${ }^{139}$ which affirms the EU's environmental competence.

Any safeguard measure initiated by a Member State relating to an instrument of harmonization within the internal market requires Commission approval (subject eventually to assessment by the CJEU) for any deviation of harmonized standards or approaches to the regulation of chemical substances. In areas where the EU has not created harmonized standards, CJEU case law traditionally has given Member States greater discretion to impose safeguard measures. ${ }^{140}$ However, where the EU has introduced harmonizing measures - as in REACH - the CJEU takes a narrower view and denies national provisions and measures if the Member State cannot provide proof of new scientific evidence of harm.

Article 114(5) TFEU specifically states that for a Member State to initiate national prohibitions, it must provide new scientific evidence of harm. Not only can finding such evidence prove challenging in cases of disputed science (not uncommon in procedures involving hazardous substances), it once again involves an expert-driven risk analysis, different from the more societal and qualitative essential use approach proposed by Cousins and co-authors. Given that no Member State prior to REACH operated an essential use policy, any such national essential use programme could arguably constitute a 'new' measure, subject to the conditions of Article 114(5) TFEU, including the proviso that the national provision be based on 'new scientific evidence relating to the protection of the environment or the working environment on grounds of a problem specific to that Member State'.

The essential use approach is of a conceptual nature, linked to societal preference and 'needs' rather than case-specific science, and not arising out of 'problems' (rather, choices) specific to a Member State. It seems unlikely, therefore, that the European Commission and the CJEU would accommodate the introduction of such a novel, society-driven concept under the file-specific approach of Article 114 TFEU - unless, that is, the law were to be amended or a new law introduced.

\subsection{Essential Use in REACH De Lege Ferenda}

There appears to be little or no obstacle to formally including an amendment of REACH, or indeed of any other EU law, so as to adopt or accommodate an essential use approach. This would be a more robust way to incorporate a substantive application of the essential use concept, rather than an over-reliance on comitology procedures

139 Art. 193 TFEU. For legislation based on the environmental title of the treaty, Art. 193 TFEU appears as a counterpart to Art. 114 TFEU; see L. Reins, 'Where Eagles Dare: How Much Further May EU Member States Go under Article 193 TFEU?', in M. Peeters \& M. Eliantonio (eds), Research Handbook on EU Environmental Law (Edward Elgar, 2020), pp. 22-35.

140 Case C-227/82, Van Bennekom, ECLI:EU:C:1983:354; Case C-174/82, Sandoz BV, ECLI:EU: C:1983:213; Case C-94/83, Heijn, ECLI:EU:C:1984:285; Case C-57/85, Mirepoix, ECLI:EU: C:1986:123; and Case C-331/88, Fedesa and Others, ECLI:EU:C:1990:391. See generally A. Alemanno, 'The Shaping of the Precautionary Principle by European Courts: From Scientific Uncertainty to Legal Certainty', in L. Cuocolo \& L. Luparia (eds), Cahiers Européens (Halley 2007), Bocconi Legal Studies 2007 Research Paper No. 1007404, available at: https:/papers.ssrn.com/sol3/ papers.cfm?abstract_id=1007404; and Zander, n. 29 above, pp. 103-16. 
as the Commission currently advocates. An amendment which has gone through the legislative process would be less vulnerable to judicial review procedures initiated by chemical manufacturers than a measure adopted by the Commission via comitology which seeks to apply and extend the concept of essential use.

Under the standard EU lawmaking procedures, any formal amendment to REACH or any other EU secondary legislation would have to be initiated by the European Commission, not by the Member States (although Member States, in practice, can put pressure on the Commission to do so). With Ursula Von der Leyen's presidency focusing on a Green New Deal, it is not beyond reason to suppose that the current Commission might consider such a move.

A second pathway would be to introduce the essential use concept into some of the EU core strategies. Instances where essential use could be part of a future or indeed existing strategy include the EU resources strategy, ${ }^{141}$ the proposed Eight Environmental Action Programme and the Circular Economy. ${ }^{142}$ Further, the core provision of EU environmental policy, Article 191 TFEU, ${ }^{143}$ itself lists 'prudent and rational utilisation of natural resources' as one of the four objectives of EU environmental policy.

At the same time, the inclusion of an essential use concept is not without its challenges. From an EU institutional point of view, it would raise a number of concerns such as the legal base on which an essential use should rest and which department would be responsible for managing the file. Further, EU law would not just sanction any kind of essential use roll-out. First of all, an essential use approach is associated more strongly with environmental protection (Article 191 TFEU) than it is with internal market harmonization (Article 114 TFEU). Introducing an amendment with a clear environmental DNA into REACH, a Regulation based on Article 114 TFEU, would pose challenges.

Secondly, an essential use approach would have to be designed with due regard to fundamental rights and freedoms enshrined in EU and international law, including the right to property. Allowing or restricting substances based on 'betterment of society' considerations must take account of principles of non-discrimination and proportionality. A wider application of the concept that goes beyond implementing decision and restriction procedures therefore seems unlikely for now. ${ }^{144}$

However, notwithstanding these challenges, the 2020 Chemicals Strategy, combined with the Commission's commitment to a Green New Deal, has undoubtedly given the

${ }^{141}$ European Commission, 'Thematic Strategy on the Sustainable Use of Natural Resources', $\operatorname{COM}(2005) 670$, 21 Dec. 2005, available at: https://eur-lex.europa.eu/LexUriServ/LexUriServ.do?uri=COM:2005:0670:FIN: EN:PDF.

142 Interestingly, the proposed Farm2Fork Strategy (European Commission, 'A Farm to Fork Strategy for a Fair, Healthy and Environmentally Friendly Food System', 20 May 2020, COM(2020) 381), which aims to reduce pesticide use by $50 \%$, does not mention the concept of essential uses; nor does the Biodiversity Strategy (European Commission, 'EU Biodiversity Strategy for 2030', 20 May 2020, COM(2020) 380).

143 Art. 191 TFEU.

${ }^{144}$ Ritscher et al., n. 3 above (which, in the context of essential uses, points to the need to define essential use, and the need to develop a systematic evaluation framework for what may be considered 'essential' so as to avoid 'regrettable' substitution). 
concept of essential use a new lease of life, enhancing the possibility of either amending the law or introducing new legislation.

\subsection{Essential Use as a Principle of EU Law}

Principles occupy a special place in EU law. ${ }^{145}$ Their introduction can come about either (i) organically, with principles being accepted as part of a policy (including a national policy, as in the case of the precautionary principle, which originated as the German Vorsorgeprinzip), and subsequently promoted to the level of an EU principle; or (ii) top-down, whereby the principle is first included at the highest level and subsequently rolled-out across EU law. Their implementation is disciplined via the CJEU reviewing whether EU secondary legislation has properly taken account of legal principles. Elevation to principle status, therefore, is an important development.

Hence, introducing an essential use approach in REACH could have far-reaching consequences. For instance, it could inspire the use of the same concept across EU product regulation and beyond and, ultimately, support the recognition of 'essential use' as a principle of EU law. Such a move might be broadly carried by EU decision makers and the public alike. However, it is clearly far too early to predict the manifestation of essential use as a general principle of EU law, even if REACH were amended to incorporate the basic concept behind this novel regulatory measure. ${ }^{146}$

\section{CONCLUSION}

The concept of essential use, as put forward by the Cousins paper, is currently not an established method or concept in international, EU, or domestic management of hazardous substances. That is not to say that it could not become so, at least in the EU context, in light of the 2020 Chemicals Strategy for Sustainability and the commitment to phase out PFAS via the REACH restrictions procedure. The specific essential use approach in the context of the Montreal Protocol is not representative of the broader use of the concept as proposed by Cousins and co-authors. That proposal goes beyond the current application of essential use as a derogation from an otherwise applicable prohibition on the use of a substance. Further, although the CJEU has supported the vocabulary of 'essential use' in two implementing decisions, the application of essential use in those two cases is more akin to 'substitution' or 'alternative use' than to 'essential use' as proposed by Cousins.

Therefore, the concept of essential use, as proposed following the Madrid and Zürich Statements, is an innovative regulatory approach to the control of potentially hazardous substances. It is novel on four fronts. Firstly, it recognizes that PFAS may still have a role to play and, therefore, does not propose a complete or outright

145 See, e.g., A. Aragao, 'Environmental Principles in the EU', in Krämer \& Orlando, n. 117 above, pp. 44962.

${ }^{146}$ For similar discussions on an 'innovation principle', see K. Garnett, G. Van Calster \& L. Reins, 'Towards an Innovation Principle: An Industry Trump or Shortening the Odds on Environmental Protection?' (2018) 10(1) Law, Innovation and Technology, pp. 1-14. 
prohibition of PFAS. Secondly, rather than assessing all 4,700 PFAS through risk analysis (the so-called 'paralysis through analysis' approach), as is currently the case, they would be classified together as a group and assumed to be hazardous rather than 'safe enough'. Thirdly, the Cousins paper places PFAS into three different categories, thus effectively distinguishing between many consumer goods on the one hand, and goods used for specific, industrial, or medical purposes on the other. Fourthly, the concept introduces an element of normative evaluation and judgement, as opposed to relying purely on scientific evaluation or economic cost-benefit analysis, as is currently the case under the precautionary principle of risk assessment and risk management.

Given the impact of the concept on many other building blocks of the EU's regulatory health and environmental priorities, its introduction would require a formal, European legislative intervention. Such a move would certainly give the concept greater legitimacy, and reduce its vulnerability to industry opposition, than if the Commission were to rely solely on comitology as a means to phase out other problematic, hazardous substances.

An essential use approach to the regulation of problematic substances could potentially simplify regulatory control for groups of hazardous substances or processes by distinguishing between non-essential, everyday consumer products, and products and processes which may be essential or critical for the functioning of society. A simplification of the rules would no doubt be welcomed by all stakeholders. We believe that with the EU in the process of shaping a substantive Green New Deal, this may be a promising and opportune moment for all stakeholders to reshape the risk analysis approach championed by the EU over the past two decades in favour of a more qualitative approach, which better reflects, incorporates and takes account of environmental needs.

The concept of essential use offers an interesting, insightful and useful regulatory tool which may well be responsive to environmental and societal concerns. Several questions remain, including how to define 'nice-to-have' products, how to incorporate environmental considerations into a substitutable uses paradigm, and how to define 'necessary for the function of society'. However, if defined satisfactorily, the concept of essential use could be a more efficient means of controlling hazardous substances than the technocratic, analytical and quantitative approach that is currently in place. 